\title{
Studying the Knocks
}

\section{How a Closer Knowledge of What Goes on in the Cylinder Might Solve the Problems of the Fuel Supply \\ By Ch̆arles F.' Kettering}

THE fuel problem, as it exists to-day, divides itself into two general classes, one of which belongs to the automotive manufacturers and the other belongs to the fuel manufacturers. However, a complete solution in either case is impossible without the hearty coöperation of both industries.

It has been only in the last two or three years that the automotive engineers have been faced with the so-called fuel problem. The gasoline formerly used was of such high volatility as to eliminate this entirely from consideration. The volatility is not to be regarded as an essential or a non-essential of a satisfactory fuel, but it has so happened that in the case of automotive fuels volatility has been, to a certain extent, a measure of the effisiency of a fuel when the difference between the lightest parts of a fuel and the heaviest parts was relatively small.

The motor problem to-day is represented by the devising of such pieces of mechanism as are necessary for a proper distribution of the fuel to the cylinders. Volatile fuels are more easily distributed than fuels which have
to be atomized.

In addition to this the motor builders can put in additional temperature controls for holding temper

both air and cylinder walls within closer limits.

When all of these things are done we still fall short of getting the result that should be expected, were this
problem purely one of mechanical treatment of fuel and problem

mixture.
The internal combustion engine is essentially a chemical device, and, until we begin to analyze the conditions which take place after the fuel starts to burn in the cylinders, we shall be disappointed in the result obtained after the things mentioned previously have been done.

The one important thing in lower gravity fuels is the fact that they give rise to the phenomenon commonly known as the knock. This is sometimes understood to be "prematuring," and is supposed to be brought about by the deposition of carbon in the combustion chamber. It has been Conclusively demonstrated. and repeatedly checked, that the knock which occurs in : motor is not caused by preignition, but is produced by the nature of the combustion, which, in turn, is controlled entirely by the molecular structure of the fuel.

It is a well-known fact that gravity is in no wise a measure of this knocking phe nomenon, as oils from the California crudes of very. low gravity give a great deal better satisfaction than a fifty gravity oil refined from Pennsylvania crudes. The reason for this is that in the California crudes there is a large percentage-roughly forty - of the so-called cyclic compounds.

A great deal of work has been done under the writer's supervision during the last three or four years, in the determination of what takes place when the heavier fuels burn in a cylinder, and a few conclusions have been arrived at, which may be briefly expressed as follows:

With lower gravity fuels it has been necessary to lower the compression. Lowering the compression has facilitated the formation of carbon; and carbon, in turn, has aggravated the knoek. The reason is simply this: Inereasing compression results in higher instantaneous temperatures, and the high instantaneous temperatures resul in a type of combustion which makes possible an exceedingly rapid rise in presure, this rise being of very short duration. Lowering the compression gets away from this, with the result that if the engine is running at low throttle, a precipitation of earbon in the combustion chamber is caused. This deposited carbon forms the best possible type of heat insulator and permits, again, the temperatures of combustion to rise above the critical temperatures of combustion to rise above the critical
point, which had been eliminated by reducing the compression.

This discussion is mentioned here for the simple purpose. Of showing that lowering compression is only a temporary remedy. Lowering compression and increasing the cylinder-bore only decreases the efficiency of the the cylinder-bore only decreases the efficiency of the
engine and as long as the fuel burns so as to produce these abnormally high pressures, we will have the knock trouble sooner or later.

It has been proved positively that certain things can be added to the fuel which would not necessarily increase its gravity, but which render the engine free from knocks. These additions to the fuel can roughly be knocks, These additions to the fuel can roughly be
divided into two classes-the high percentage class and mean from twenty to forty per-cent and by low percentage class we mean from one-half to three per cent. and if the engine in which this mixture is used is running in the way of carbon deposits, etc. practical. mercial proposition is entirely out of the question, and it is only cited here as an example. as sulphuric ether, which is one of the lightest fuels that liminary thing so that the matter of crude is available as gasoline, twelve per cent as kero-

the low percentage class. By high percentage class we

An example of the former is an introduction of benzol. Forty per cent benzol mixed with ordinary commercial kerosene makes an engine operate entirely satisfactorily, at or near its full load, no bad results will be experience

An example of the latter case is that of iodine. One or two per cent of iodine added to oxdinary kerosene wil reduce its knock-producing property to an entirely negligible point. It will permit the use of high compressions, result in cleaner combustion and, outside of difficulty in starting, make a lower gratity fuel entirely

We understand fully that the use of iodine as a com-

The knock-producing ability of a fuel is not a function of its gravity, as might be gathered from the foregoing, we have, is also one producing the most intense knock We have discussed this knock proposition as a pre-

As oil men fully understand, about twenty per cent sene, approximately fifty per cent as gas and fuel oil, and tie remainder as lubricating oil and residue products. A

THE volatility of a fuel is not inherently a measure of its efficiency. But internal combustion fuels must be distributed properly to the cylinders; and the ease with which this may be done depends upon atility. This property therefore takes on an importance to which its ntrinsic value does not entitle it. Until we begin to analyze closely itions governing fuel combust ng with a chemical engine and must bring chemistry to bear in the ffort to solve the problems that it brings up; and he gives a number of ggestions as to how this may be done.

large per cent of gas and fuel oil could be refined into a water white oil and this, were it not for its knocking tendencies as a fuel ${ }_{2}$ is one of the most hopeful sources of increased supply. We also understand the extent to which oils are being cracked into gasoline. It is understood, also, that, if it were possible to cut down into the gas and fuel-oil section, we would have to make certain modifications in the fuel-feeding devices, in order to facilitate the matter of distribution.

It therefore seems to the writer to be of great importance that the oil people, through their processes of refining, should study those things which can be introduced into a fuel to prevent the rapid rises in pressure when certain that lower gravity fuels are burned.

It might be of interest to know that a fuel which will not knock under normal conditions, will not produce abnormal rise in pressure, even though the fuel be fired far in advance of the normal point of ignition. So that a fuel, which would not knock normally, will not knock, even though the engine is heated to the point at whioh preignition will occur.

It is also definitely understood that the temperature of the cooling water in an engine may or may not greatly effect the temperature of the explosive mixture during the process of combustion, as the thickness of cylinder walls, condition of carbon inside of the cylinders, etc., may be such that the engine, from external appearances, will be running perfectly cool, and yet the conditions inside the cylinders will be such as to bring the temperaturs of the mixture during combustion above the critical poir $t$, at, which the knock occurs.

It looks to the writer as though one of the fundamental problems involved in this is a study of the chemistry of the products formed during the process of combustion. As these are in no wise simple reactions, they are rather difficult to determine and experiments intended to discover their nature must be made in a more or less empirical way.

An illustration of the type of combustion which takes place is as follows: If a piece of celluloid be ignited by of any flame; if lighted by a match, the phenomenon of inflammability will at once be shown. The celluloid itself is not inflammable, but the gases formed by the decomposition of the celluloid are extremely inflammable: When the celluloid is ignited by a cigar butt the temperature does not rise sufficiently high to cause ignition of the vapors which are formed. When lighted y a match, these two combustions occur simultaneously.

Pressure and temperature have a tremendous effect upon the way in which compounds burn. It is well known that when smokeless powder is lighted in the open air by match or cigar butt, it will burn without any rapid rise in pressure, but if the products of this primary combustion be confined so that both temperature and, pressure rise, the result is quite different and tremendouts presure is developed.

From our,expertmental work it appears to us that similar to the above take place when we burn molecules of our present-day fuels, that. and and rapid rise in pressure resulting from the known as the knock.

It is the writer's firm conviction that it is pose mentioned before, to refine present crudes into motor fuel and to deal more of our satisfactory results in engines of very much higher pressions than those now used, if we can control the way in which the fuel molecules break downRead at Automotive Fuel Dinner in New York.

\section{Grade Crossing Construction}

Only a few railroads have yet adopted such excellent substitutes for lumber asphalt, concrete, macadam, etc., for farm street and highway crossing construction, although concrete is not a novelty on railroads, as for years past its value and use fulness have been developing. A report from one supervisor's division shows the it required 53,678 feet of lumber, 3,226 pounds of crossing spikes and a labor charge of $\$ 5,642.96$ to maintain the public and private crossings on his territory for one year, the cost of the plank alone being $\$ 1,717.70$. If this amount of lumber can be conserved on one division, assuming that it requires 512 eet for one single track crossing, or twice the amount for double track, and assuming also that there are 50 or more highway crossings on each of 3,000 supervisors' divisions on the railways of the country, the use of some other material than lumber would mean the conservation of $76,800,000$ feet, amounting to $\$ 2,457,600$.

Since a crossing must be kept up continually, the method of maintaining it should be so simple as to be grasped readily by the average workman. To be practical, the work should be performed with the least possible equipment and this should be of such character as wil always be at hand. To be economical, the expense must be within reason and not exceed that of other methods and materials that are used for work of like nature producing like results.

As far as possible all rail joints should be eliminated in road crossings; good drainage should be installed, and all road crossings in high speed tracks should be made of crushed stone of standard size, mixed either with good road oil, bituminous macadam, asphalt or other good substitutes for. lumber. In parts of the country where there is considerable frost and where tracks hesve the sealing of the crossings with these substitutes will keep out the moisture and frost and eliminate the heaving of tracks to a considerable extent, also the heaving of crossing planks, which is a source of danger.

Excellent results have been obtained with crossings constructed of good clean crushed stone (ballast size), from a depth of 2 inches below the bottom of the ties up to the level of the under side of the head of the rail, and extending 2 feet outside the rails, rolling or tamping it thoroughly, the rails having first been painted with hot asphalt below the under side of the head, and a mixture of fine crushed stone and hot asphalt being packed about them for a distance of 8 inches on each side. The entire crossing is then covered with fine stone up to the level of the top of the rails, sprinkling it freely with a good quality of road oil, while fine stone is scattered. 